\title{
Comparative Study of Prevalence and Correlates of Mental Health Problems in Deaf and Hearing Adolescents in a Semi-Inclusive Setting in Ibadan, Southwest Nigeria
}

\author{
Yetunde Adeniyi ${ }^{1,2, *}$, Olayinka Omigbodun ${ }^{1,2}$, Aderemi Adeosun ${ }^{3}$ \\ ${ }^{1}$ Department of Child and Adolescent Psychiatry, University College Hospital, Ibadan, Nigeria \\ ${ }^{2}$ Department of Psychiatry, University of Ibadan, Ibadan, Nigeria \\ ${ }^{3}$ Department of Otorhinolaryngology, University of Ibadan and University College Hospital, Ibadan, Nigeria \\ Email address: \\ pcyetty@yahoo.com (Y. Adeniyi) \\ ${ }^{*}$ Corresponding author
}

\section{To cite this article:}

Yetunde Adeniyi, Olayinka Omigbodun, Aderemi Adeosun. Comparative Study of Prevalence and Correlates of Mental Health Problems in Deaf and Hearing Adolescents in a Semi-Inclusive Setting in Ibadan, Southwest Nigeria. American Journal of Psychiatry and Neuroscience. Vol. 7, No. 1, 2019, pp. 1-7. doi: 10.11648/j.ajpn.20190701.11

Received: January 18, 2019; Accepted: February 18, 2019; Published: March 5, 2019

\begin{abstract}
Adolescents with deafness exhibit higher mental health problems when compared with their hearing peers. There is limited information on the mental health problems of adolescents with deafness living in the sub-Saharan Africa. The aim of this study was to determine the prevalence of mental health problems in a group of deaf adolescents and the relationship with socio-demographic characteristics and to compare with their hearing counterparts. Materials and Methods: Teachers of 102 deaf adolescents and 102 age- and sex-matched hearing adolescents completed the Strengths and Difficulties Questionnaire (SDQ). Severity of deafness was assessed using Pure Tone Audiometry, using a five-frequency average. Results: The results showed that $88.2 \%$ and $11.8 \%$ of the deaf participants had profound and severe forms of deafness respectively. The prevalence of behavioural problems was significantly higher in the deaf adolescents than the control, as assessed by their teachers' $(64.3 \%$ vs. $35.7 \% ; p<0.001)$. Ninety seven percent of the deaf participants reported no hearing aids use. Parental separation/divorce and mother's educational status were significantly associated with higher rates of behavioural problems $(p<0.05)$. There was no significant association between severity of impairment and mental health problems. Conclusion: Almost all the factors associated with deafness that are highlighted in this study are preventable through appropriate health and social interventions such as hearing aids, and will require that appropriate policy measures are put in place.
\end{abstract}

Keywords: Adolescents, Deafness, Mental Health Problems, Sub-Saharan Africa

\section{Introduction}

There appears to be no information on the prevalence and correlates of mental health problems among deaf adolescents living in sub-Saharan Africa. The available studies done among deaf adolescents living in Africa mostly focused on other comorbidities especially HIV/AIDS, reproductive health and sexual abuse $[1,2]$. This lack of information is despite the fact that $25 \%$ of the 32 million children and adolescents with deafness worldwide live in Africa [3].

Varying prevalence of deafness among adolescents have been reported all over the world, for example a study in the
United States of America reported that $20 \%$ of adolescents have some degree of deafness. In Nigeria, a study that was done among children and adolescents found a prevalence of $39.4 \%$ of different degrees of deafness [4]. This high prevalence of deafness in developing countries is considered to be a consequence of factors such as high prevalence of preventable childhood infections, absent or inadequate screening programmes for ear diseases [5], poor access to health care and a lack of adequate vaccines [3].

Deafness is associated with mental health problems [6] and it has been documented that early onset of significant hearing impairment can have a life-long effect on a child's development, and may result in adverse consequences for 
mental health; both in childhood and adult life [7, 8]. Studies among children and adolescents with deafness have reported higher rates of mental health problems than their hearing counterparts [7]. For example, an Australian study assessed 99 children with bilateral deafness of at least $40 \mathrm{~dB}$ where parents and teachers completed the Strengths and Difficulties Questionnaire (SDQ) [9]. Results indicated that children with deafness scored significantly higher on the SDQ than their counterparts from normative samples according to both parents' and teachers' ratings [9]. In another study of adolescents with deafness, $46 \%$ reported different types of mental health problems [10]. Some significant impacts of mental health problems occurring with deafness include increased social isolation and academic difficulties, this is usually a result of frequent absence from school and other school-related social activities [11].

The above studies were done in other continents of the world, there is currently no information on the prevalence of mental health problems and socio-demographic correlates among deaf adolescents living in Africa. The current study aimed at investigating the prevalence and correlates of mental health problems among school-going deaf adolescents in Nigeria, West Africa.

\section{Materials and Methods}

\subsection{Study Site and Participants}

The participants were adolescents attending a Secondary School in Ibadan, South-West Nigeria. The school compound is divided into 2 distinct segments. The first segment, closer to the main entrance and bigger, is the mainstream school consisting of about 800 students while the second is a School for the Deaf consisting of about 150 students. The mainstream school has a playground that is distinct from the school for the deaf but share other facilities like the library, cafeteria with the hearing students. Adolescents who were older than 16 years of age were excluded from the study. Of 111 deaf adolescents who met the criteria, parents of 9 did not give informed consent and were thereby excluded from the study, therefore a hundred and two adolescents with deafness participated in the study. Equal number of hearing adolescents from the mainstream arm of the school was recruited as the control group, they were matched for age and sex with the adolescents with deafness. The participants consisted of 47 males and 55 females in each group with a mean age of 15.2 years (range 13-16 years).

Teachers of all the participants in both groups completed the teachers' versions of the SDQ. The study was approved by the University of Ibadan/University College Hospital Ethical Review Committee and parents/caregivers of all the participants provided written consents. All analyses were performed with SPSS version 20.

\subsection{Socio-Demographic and Clinical Data Collection}

This is a 15-item data collection form developed by the investigators to collect information on the socio-demographic profile and clinical characteristics including age of onset of deafness, cause of deafness and use of hearing aid.

\subsection{Mental Health Problems Rating}

The Strengths and Difficulties Questionnaire (SDQ) [12] was used to measure mental health problems. This is one of the most widely used measurement tools in child and adolescent mental health around the world. The SDQ consists of 25 items that are divided between 5 scales namely emotional, hyperactivity, conduct, peer problems and prosocial scales. The scores from the first four scales are added together to give a "total difficulties" score. The prosocial scale is a measure of behavioural strength, these behaviours relate to positive social interactions and behaviours. The SDQ can be completed by parents or teachers for children ages 4-16 years and there is a self-report version for young people aged 11 years and older. The SDQ was originally developed and validated within the United Kingdom and its reliability and validity have been replicated in several countries including Nigeria [13]. Its use among individuals with deafness have been established [14].

\subsection{Determination of Severity of Deafness}

An otorhinolaryngologist conducted audiological assessment on the adolescents with deafness. This assessment was carried out in two stages; the first stage was otoscopy which involved the examination of both ears of the participants for deformities and wax impaction. Participants with wax impaction were reassessed after the wax was softened and removed. The second stage of the audiological assessment process was Pure Tone Audiometry (PTA) where both bone and air conduction methods were used and readings in decibels $(\mathrm{dB})$ were taken at five different frequencies; $500 \mathrm{~Hz}, 1000 \mathrm{~Hz}, 2000 \mathrm{~Hz}, 3000 \mathrm{~Hz}$ and 4000 $\mathrm{Hz}$. Using a five-frequency average, severity of deafness was classified, using the WHO guideline, as profound $(\geq 81 \mathrm{~dB})$, severe (61-80dB), moderate (41-60dB), slight impairment (26-40dB) and no impairment $(\leq 25 \mathrm{~dB})$. Majority of the participants in the study group had profound deafness $(n=90)$ and the remaining 12 had severe deafness.

\section{Results}

\subsection{Characteristics of the Participants}

Table 1 shows a significantly higher percentage (35.3\%) of the deaf participants came from polygamous family setting as compared with $19.6 \%$ from the hearing group; this difference in their family type was statistically significant $(\mathrm{p}=0.012)$ and more deaf participants tended to have parents who were not married $(p=0.017)$. A significantly higher proportion of the mothers in the deaf group had no formal education $(\mathrm{p}<$ $0.011)$.

\subsection{Clinical Variables of Participants with Deafness}

Majority $(63.7 \%)$ of the deaf participants were diagnosed 
before 5 years of life. Many of the participants' parents reported infection as the cause of their deafness and the use of hearing aid was low with $95.1 \%$ reporting no use (Table $1)$.

Table 1. Socio-demographic and Clinical Characteristics of Participants.

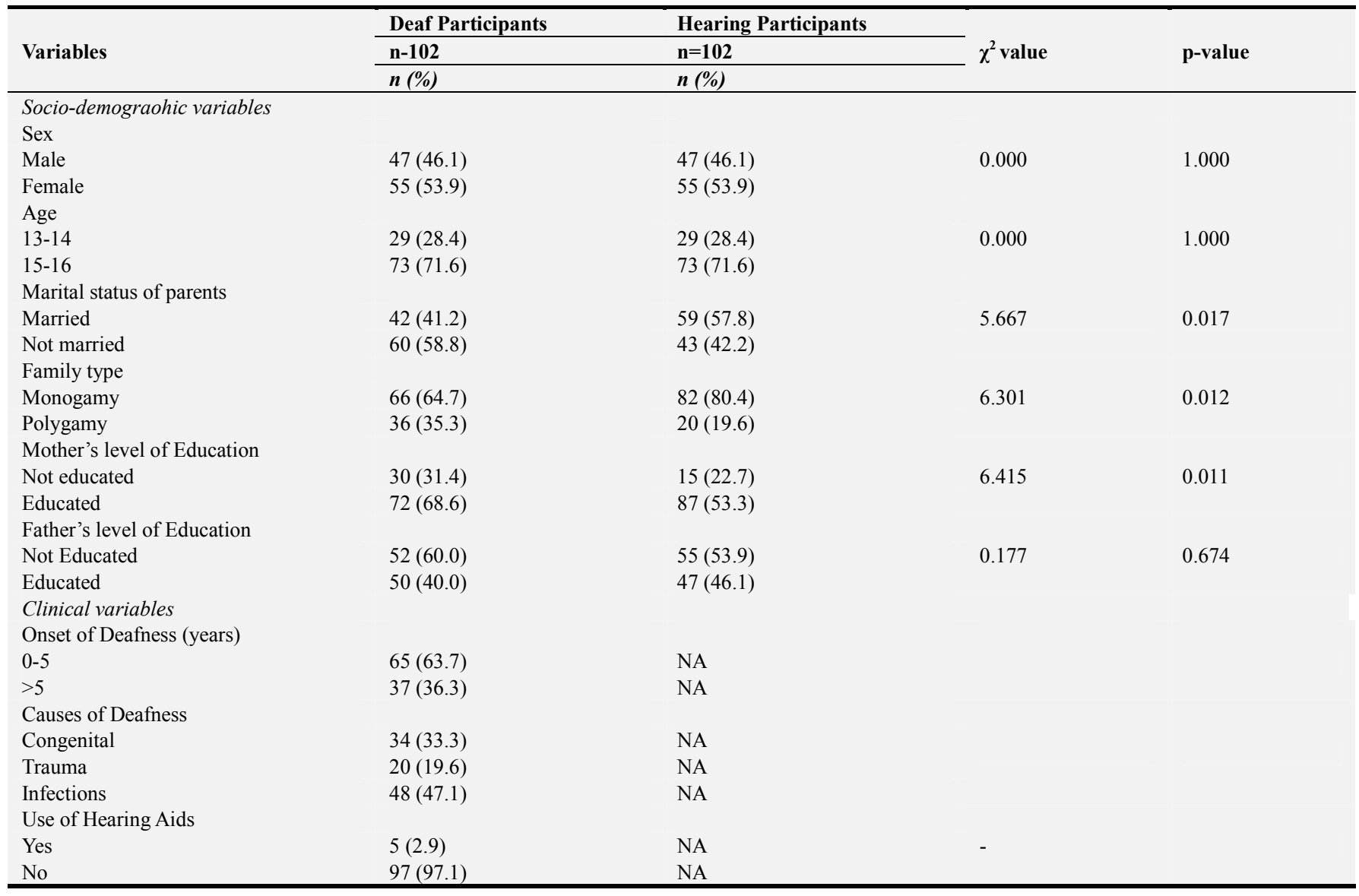

$\mathrm{NA}=$ Not Applicable.

The significance values $(\mathrm{p}<0.05)$ are in bold.

\subsection{Logistic Regression Analysis}

Table 2 summarises the results from the logistic regression analyses showing the odds ratio for the variables that reached statistical significant in the univariate analyses in Table 1. The results showed that deaf participants were about 2 times more likely to have come from polygamous family settings ( $\mathrm{OR}=1.99,95 \% \mathrm{CI} 1.02-3.86)$, to have parents who were not married $(\mathrm{OR}=1.95,95 \% \mathrm{CI} 1.09-3.49)$ and less likely to have mothers who were educated $(\mathrm{OR}=0.28,95 \% \mathrm{CI}$ 0.10-0.83).

Table 2. Logistic regression for Socio-demographic variables.

\begin{tabular}{lcc}
\hline Variables & OR $\mathbf{( 9 5 \%} \mathbf{C I})$ & p-value \\
\hline Mother's educational level & $0.283(0.096-0.836)$ & 0.022 \\
No education* & & \\
Educated & $1.987(1.022-3.863)$ & 0.043 \\
Family type & & 0.019 \\
Monogamy* & $2.192(1.139-4.217)$ & \\
$\begin{array}{l}\text { Polygamy } \\
\text { Religion }\end{array}$ & & 0.025 \\
Christianity* & $1.947(1.086-3.491)$ & \\
Others (Islam/Traditional) & & \\
Marital status of parents & & \\
Married* & & \\
\hline
\end{tabular}

*reference category.

Note- The significance values $(\mathrm{p}<0.05)$ are in bold. 


\subsection{Prevalence and Correlates of Mental health Problems}

Over half of the deaf group (65.5\%) obtained a total difficulty score of 14 (cut-off point obtained from the validation of SDQ done in Nigeria) [13] and above on the SDQ as assessed by the teachers as compared with $34.5 \%$ in the hearing group (Table 3). There were significant differences between the SDQ classification into cases $(\mathrm{SDQ} \geq 14)$ and non-cases $(<14)$ as assessed by the teachers $\left(\chi^{2}\right)=1.30$; $p<$ 0.001]. An analysis of the associations between sociodemographic variables and mental health problems was carried out and the results are seen in Table 4. Mental health problems are significantly higher among participants whose mothers have no formal education in both the deaf $(p<0.001)$ and hearing group $(\mathrm{p}=0.005)$. Deaf participants whose parents were not married $(p<0.001)$ and whose deafness started before 5 years of age $(p=0.040)$ have significantly higher level of mental health problems. None of the 5 participants that reported use of hearing aids belong into the category of participants classified as 'cases', this association between hearing aids use and mental health problems was statistically significant $(p=0.037)$ There was no significant association between severity of deafness and mental health problems.

Table 3. Prevalence of behavioural problems based on teachers' rating of the $S D Q$ in both groups.

\begin{tabular}{llll}
\hline & Cases & Non cases & \\
\cline { 2 - 3 } & $\mathbf{S D Q} \geq \mathbf{8}$ & $\mathbf{S D Q}<\mathbf{8}$ & \\
\hline & $\mathbf{n}=\mathbf{8 5}$ & $\mathbf{n}=\mathbf{1 1 9}$ & $\left(\chi^{2}\right)=12.81$ \\
\hline Deaf Group & $55(65.5)$ & $47(39.2)$ & $\mathrm{p}<0.001$ \\
\hline
\end{tabular}

Note- The significance values $(\mathrm{p}<0.05)$ are in bold

Table 4. Association between Socio-demographic variables and mental health problems in the two groups.

\begin{tabular}{|c|c|c|c|c|c|c|c|c|}
\hline \multirow[b]{2}{*}{ Variables } & \multicolumn{4}{|c|}{ Deaf Group } & \multicolumn{4}{|c|}{ Hearing Group } \\
\hline & $\begin{array}{l}\text { Cases } \\
\mathrm{n}=55\end{array}$ & $\begin{array}{l}\text { Non cases } \\
\mathrm{n}=47\end{array}$ & $\chi^{2}$ & P value & $\begin{array}{l}\text { Cases } \\
\mathbf{n}=\mathbf{3 0}\end{array}$ & $\begin{array}{l}\text { Non Cases } \\
\mathrm{n}=72\end{array}$ & $\chi^{2}$ & P Value \\
\hline Age (years) & $\mathrm{n}(\%)$ & $\mathrm{n}(\%)$ & & & $\mathrm{n}(\%)$ & $\mathrm{n}(\%)$ & & \\
\hline $13-14$ & $14(25.5)$ & $15(31.9)$ & 0.520 & 0.471 & $10(33.3)$ & $19(26.4)$ & 0.502 & 0.407 \\
\hline $15-16$ & $41(74.5)$ & $32(68.1)$ & & & $20(66.7)$ & $53(73.6)$ & & \\
\hline \multicolumn{9}{|l|}{ Sex $n$} \\
\hline Male & $22(40.0)$ & $25(53.2)$ & 1.775 & 0.183 & $15(50.0)$ & $32(44.4)$ & 0.354 & 0.552 \\
\hline Female & $33(60.0)$ & $22(46.8)$ & & & $15(50.0)$ & $40(55.6)$ & & \\
\hline \multicolumn{9}{|l|}{ Family type } \\
\hline Monogamy & $38(69.1)$ & $28(59.6)$ & 1.005 & 0.318 & $26(86.7)$ & $56(77,8)$ & 1.061 & 0.303 \\
\hline Polygamy & $17(30.9)$ & $19(40.4)$ & & & $4(13.3)$ & $16(22.2)$ & & \\
\hline \multicolumn{9}{|c|}{ Marital status of parents } \\
\hline Married & $13(23.6)$ & $29(61.7)$ & 15.161 & $<0.001$ & $16(53.3)$ & $43(59.7)$ & 0.354 & 0.552 \\
\hline Not Married & $42(76.4)$ & $18(38.3)$ & & & $14(46.7)$ & $29(40.2)$ & & \\
\hline \multicolumn{9}{|c|}{ Mother's Educational status } \\
\hline Educated & $29(52.7)$ & $41(87.2)$ & 14.02 & $<0.001$ & $19(63.3)$ & $63(87.5)$ & 7.846 & 0.005 \\
\hline Not Educated & $26(47.3)$ & $6(12.8)$ & & & $11(36.7)$ & $9(12.5)$ & & \\
\hline \multicolumn{9}{|c|}{ Onset age of deafness (Years) } \\
\hline $0-5$ & $40(72.7)$ & $25(53.2)$ & 4.184 & 0.040 & NA & NA & & \\
\hline$>5$ & $15(27.3)$ & $22(46.8)$ & & & & & & \\
\hline \multicolumn{9}{|c|}{ Cause of Deafness } \\
\hline Congenital & $16(29.1)$ & $18(38.3)$ & & & & & & \\
\hline Trauma & $14(25.5)$ & $6(12.8)$ & 2.791 & 0.248 & NA & NA & & \\
\hline Infections & $25(45.4)$ & $23(48.9)$ & & & & & & \\
\hline \multicolumn{9}{|c|}{ Use of Hearing Aid } \\
\hline Yes & $0(0.0)$ & $5(10.6)$ & & *0.037 & NA & NA & & \\
\hline No & $55(100)$ & $42(89)$. & & & & & & \\
\hline
\end{tabular}

*Fisher's exact, NA= Not applicable.

Note- The significance values $(\mathrm{p}<0.05)$ are in bold.

\section{Discussion}

The objective of the study was to find the prevalence of mental health problems and their associations with sociodemographic characteristics and clinical variables. More adolescents in the deaf group than the hearing group were from polygamous family settings. A possible explanation for the higher rate of polygamy among the deaf participants might be the effect of the presence of a child with a disability on family stability. In some African cultures, it has been 
suggested that a woman's status in a family is directly related to her ability to produce strong heirs and thus a woman who gives birth to a disabled child is less able to compete for the husband's attention and the husband might decide to take in another wife [15]. Another reason for the observation could be the effect of polygamy on the children in the family. It has been shown that polygamy affects the general health of children within the family and they are likely to present with more health problems than children from monogamous families [16]. Studies have also found a significant association between polygamy, and low savings rates, a high incidence of infectious diseases, high levels of child morbidity and mortality and maternal depression in pregnancy [17]. All these factors increase the risk of a child having a disability. The large sizes of polygamous families also tend to reduce the amount of support, including financial support and parental stimulation received by the children, further increasing the risk of deafness.

There was also a higher report of non-married parents in the deaf participants; which is in keeping with previous studies. Results from a study in the Netherlands showed that $38 \%$ of deaf children as opposed to $25 \%$ of the hearing children came from one parent families [18]. This might be as a result of the fact that deafness is a chronic and disabling condition, it has been documented that childhood chronic illnesses and disability are major sources of family distress and dysfunction which could lead to family discord. Studies have also shown that raising a child with a disability causes marital strain and increases the probability of divorce or separation [19]. In addition, parenting demands and stress are higher among parents of children with deafness [18] leaving little room for a renewed marital relationship between the parents. Other factors that can lead to parental separation are societal stigma on families with adolescents with disabilities [18] and extended family practice in Nigeria which allows for significant interference in the decisions within the nuclear family [19]. Another possible explanation of this observation is that deafness in a child could also be a consequence of an already strained marriage. This is because the parents are usually preoccupied with the marital difficulties and discord and may neglect the care and supervision of children or care during the ante-natal period [20]. This might lead to a higher risk of having a child with deafness. It may therefore be reasonable to conclude that the relationship between marital status of the parents and deafness in the child found in this study may actually be multifaceted and bidirectional.

A significantly higher percentage of mothers in the deaf group had no formal education; this is consistent with previous studies showing a higher rate of low educational attainment in mothers of children with deafness. In a study that assessed the socio-demographic characteristics of deaf and hearing children, it was found that more parents in the deafness group had no or low educational level attainment [18]. An explanation for this is that mothers who have no formal education might be limited in their ability to make informed decisions about the health of their children and might also have difficulty accessing health care for them.
Utilization of ante-natal care by mothers who are not educated might be limited and this in turn may lead to an increased risk of complications like brain infection in the baby that can subsequently lead to deafness. Protective mechanisms against hearing disability have been associated with more maternal education [21], these mechanisms include less maternal depression, ability to access and benefit from interventions and having a better nutritional status [21].

Only 5 of the 102 deaf participants reported the use of hearing aids, there has been a consistent report of underutilisation of hearing aids in the developing world. Some of the reasons given for the under-utilisation of hearing aids in the developing world are non-affordability, unavailability and stigmatisation attached to deafness which can be worsened by the use of hearing aid. All the 5 participants who reported the use of hearing aid did not fall into the category of those classified as "cases" with mental health problems. It is expected that the use of hearing aids will reduce the amount of hearing difficulties experienced by the user, improving their functioning in society by enabling them to hear better and that this will assist them to communicate effectively. This will further reduce agitation and other behavioural problems. Previous studies that examined the effect of hearing aid use on behavioural problems found a significant reduction in the level of behavioural problems with hearing aid use [22].

The above factors; polygamy, parental separation, low maternal level of education and low use of hearing aids, are all related to poverty. For example, the level of education of a child's parent especially the mother is linked to poverty and it is one of the strongest predictors of the child's health [23]. Also, a very small proportion of the adolescents with deafness reported the use of hearing aids. It has been reported that in developing countries only about $3 \%$ of the people who require hearing aids have them [24]. This is mainly due to poverty, as one hearing aid could cost between $\$ 1800$ and $\$ 6800$, in addition to the stress of replacing the batteries weekly [24]. It is an established facts that about $50 \%$ of people living in subSaharan Africa lives below \$1.25/day [25, 26].

The prevalence of mental health problems found in this study is higher among the deaf participants than the hearing control. This is consistent with previous findings that children and adolescents with deafness had higher rates of behavioural problems than their hearing counterparts $[8,27]$. A consistent explanation for the higher mental health problems among deaf adolescents is poor language development. Previous studies have reported strong links between language and behaviour problems, with children diagnosed with language disorders showing a higher prevalence of behaviour problems and vice versa [28]. Other reasons that have been given for the increased prevalence of behavioural problems include poor child-parent relationship, poor socio-economic state and the mode of communication within the family.

\section{Conclusion}

In conclusion, the current study indicated that deaf 
adolescents have significantly higher level of mental health problems when compared with their hearing counterpart, and these high levels of mental health problems are associated with low educational attainment of mothers of both the deaf and hearing participants. Both deafness and low maternal education are potentially remediable through appropriate health and social interventions such as hearing aids but at present, the provision of such interventions is far from been adequate in most parts of Africa. Half of the causes of hearing loss are preventable by primary means and some of the causes require some major policy decisions to be dealt with.

\section{Abbreviation}

SDQ: Strengths and Difficulties Questionnaire.

\section{References}

[1] Sangowawa A O, Owoaje E T, Faseru B, Ebong I P, Alagh B T. A comparative study of HIV/AIDS knowledge and attitudes of hearing-impaired and non-hearing-impaired secondary school students in Ibadan. Niger J Clin Pract 2010; 13: 453-8

[2] Issaka, Alimatu Cecilia. "Gender perspective of HIV/AIDS Knowledge and sexual behaviour of adolescents with hearing impairment in selected special schools in Ghana." Advances in Social Sciences Research Journal 5. 12 (2018).

[3] World Health Organization. "Childhood hearing loss: strategies for prevention and care." (2016).

[4] Oyewumi and Adeyemo. An Investigation of Hearing Loss among School Age Children through Audiological Assessment in Ibadan, Oyo State, Nigeria. Elementary Education Online 2011; 10 (1), 1-11.

[5] Asonye, Emmanuel Ihechi, Ezinne Emma-Asonye, and Mary Edward. "Deaf in Nigeria: A Preliminary Survey of Isolated Deaf Communities." SAGE Open 8. 2 (2018): 2158244018786538 .

[6] Hogan., Phillips, R. L., Howard, D. \& Yiengprugsawan, V. Psychosocial outcomes of children with ear infections and hearing problems: a longitudinal study. BMC Pediatrics 2014; 14:65 doi:10.1186/1471-2431-14-65.

[7] Fellinger J, Holzinger D, \& Pollard R. Mental health of deaf people. Lancet 2012, 379, (9820):1037-1044.

[8] Hogan, A., Shipley, M., Strazdins, L., Purcell, A., \& Baker, E. Communication and behavioural disorders among children with hearing loss increases risk of mental health disorders. Australian and New Zealand Journal of Public Health 2011; 35 (4), 377-383.

[9] Adigun, O. T. "Depression and Individuals with Hearing Loss: A Systematic Review." Journal of Psychology and Psychotherapy 7.5 (2017): 1-6.

[10] van Gent T, Goedhart AW, Hindley PA. \& Treffers, PDA. Prevalence and correlates of psychopathology in a sample of deaf adolescents. Journal of Child Psychology and Psychiatry 2007, 48, 950-958.

[11] Kouwenberg, M., Rieffe, C., Theunissen, S. C. P. M., \&
Oosterveld, P. Pathways Underlying Somatic Complaints in Children and Adolescents Who Are Deaf or Hard of Hearing. Journal of Deaf Studies and Deaf Education 2012; 17, 319332 .

[12] Goodman, R. The Strengths and Difficulties Questionnaire: A Research Note. Journal of Child Psychology and Psychiatry $1997,38,581-586$

[13] Adeniyi Y and Omigbodun O. Psychometric Properties of the Self-report Strengths and Difficulties Questionnaire (SDQ) in a Nigerian Adolescents Sample. International Neuropsychiatric Disease Journal, 2017 10(2): 1-9. DOI: 10.9734/INDJ/2017/37760.

[14] Hintermair M. Prevalence of socio-emotional problems in deaf and hard of hearing children in Germany. American Annals of the Deaf 2007; 152, 320-330.

[15] Schlebusch, Liezl, Shakila Dada, and Alecia E. Samuels. "Family quality of life of South African families raising children with autism spectrum disorder." Journal of autism and developmental disorders 47.7 (2017): 1966-1977.

[16] Lawson, David W., and Mhairi A. Gibson. "Polygynous marriage and child health in sub-Saharan Africa: What is the evidence for harm?." Demographic Research 39 (2018): 177208.

[17] van Gent T, Goedhart AW. \& Treffers PD. (2012). Characteristics of children and adolescents in the Dutch national in- and outpatient mental health service for deaf and hard of hearing youth over a period of 15 years. Research in developmental Disability 2012, 33, 1333-1342.

[18] Cuzzocrea, Francesca, et al. "Parental stress, coping strategies and social support in families of children with a disability." Child Care in Practice 22.1 (2016): 3-19.

[19] Ajayi J. O., Owumi B. (2013). Socialization and Child Rearing Practices among Ethnic Groups in Nigeria. Academic Journal of Interdisciplinary Studies, 2, 249-256.

[20] Amato, R. \& Booth, A. (2010). The Legacy of Marital Discord: Consequences for Children's Marital Quality." Journal of Personality and Social Psychology, 81 (4), 627-38.

[21] Walker SP, Wachs TD, Grantham-McGregor S, Black MM, Nelson CA, Huff man SL, Baker Henningham H, Chang SM, Hamadani JD, Lozoff B (2011):Inequality in early childhood: risk and protective factors for early child development. Lancet 2011; 378: 1325-1338.

[22] Doshi, J., McDemott, A., Reid, A., \& Proos (2010). The use of a bone-anchored hearing aid (Baha1) in children with severe behavioural problems - The Birmingham Bahal programme experience. International Journal of Pediatric Otorhinolaryngology, 74, 608-610.

[23] Adekanmbi V. T., Kandala N. B., Stranges S. and Uthman O. A, (2015). Contextual socioeconomic factors associated with childhood mortality in Nigeria: a multilevel analysis. Journal of Epidemiology and Community Health. pii: jech-2015205457. doi: 10.1136/jech-2015-205457.

[24] World Health Organisation (2013). Technology Transfer Aids Hearing. Bulletin of World Health Organisation, 91, 471-472.

[25] World Bank (2015). World Development Indicators Database. http://data.worldbank.org/. Accessed 17 June 2015. 
[26] AFDB (2013) Federal Republic of Nigeria Country Strategy Paper 2013-2017. Tunis: African Development Bank Group.

[27] Stevenson, J., McCann, D., Watkin, P., Worsfold, S. \& Kennedy, C. (2010). The relationship between language development and behaviour problems in children with hearing loss. Journal of Child Psychology and Psychiatry, 51, 77-83.
[28] Levickis, Penny, et al. "Language and social-emotional and behavioural wellbeing from 4 to 7 years: a community-based study." European child \& adolescent psychiatry 27.7 (2018): 849-859. 